\title{
Circuit Breaker Device
}

National Cancer Institute

\section{Source}

National Cancer Institute. Circuit Breaker Device. NCI Thesaurus. Code C50347.

A device designed to open an electrical circuit when it becomes overloaded. 